\title{
MUDANC̣AS NECESSÁRIAS NA UNIVERSIDADE BRASILEIRA: AUTONOMIA, FORMA DE GOVERNO E INTERNACIONALIZAÇÃO
}

\author{
Fernando Seabra Santos* \\ Elimar Pinheiro do Nascimento** \\ Cristovam Buarque ${ }^{* * *}$
}

RESUMO: A partir de um breve percurso sobre as mais importantes reformas universitárias ocorridas no último século, notadamente a de Gilman-Flexner, concretizada nos Estados Unidos a partir de 1910, e a do chamado Processo de Bolonha, iniciado na Europa em 1999, a posição e o papel da universidade moderna é analisado no contexto da constituição e da consolidação de uma sociedade do conhecimento, com uma particular atenção para o caso brasileiro. São passadas em revista os grandes desafios e as maiores fragilidades do sistema de educação superior do Brasil e defendidas políticas de inclusão, de qualidade, de inovação e de internacionalização das IES brasileiras num quadro de autonomia administrativa e financeira reforçada e de profunda reforma das atuais formas de governo e dos modelos de gestão.

Palavras-chave: Reforma Universitária; Sociedade do Conhecimento; Autonomia; Internacionalização; Governo.

\section{NECESSARY CHANGES IN BRAZILIAN UNIVERSITY: AUTONOMY, GOVERNANCE AND INTERNATIONALIZATION}

ABSTRACT: Starting with a brief description of the main university reforms of the last century, namely the Gilman-Flexner reform that came into practice in the United States as from 1910 and the so called Bologna Process, launched in 1999 in Europe, the position and role of modern university is addressed within the framework of the creation and consolidation of a knowledge society. Special attention is given to the Brazilian case study. The main challenges and weaknesses of the Brazilian higher education system are analyzed, as to support strategies of inclusion, quality, innovation and internationalization of higher education institutions, together with the empowerment of their administrative and financial autonomy, as well as of a profound reform of present governance and management models.

Keywords: University Reform; Knowledge Society; Autonomy; Internationalization; Governance.

\footnotetext{
*Professor Catedrático, Universidade de Coimbra; Foi bolsista da CAPES (Programa CAPES/PVE) entre Abril de 2011 e Setembro de 2012. E-mail: fseabra@unb.br

* *Professor Associado II, Universidade de Brasília (UNB). E-mail: elimarcds@gmail.com

***Professor Titular, Universidade de Brasília (UNB). E-mail: buarquecristovam@gmail.com
} 


\section{INTRODUCุÃO}

A centralidade do papel do conhecimento na sociedade moderna e no sucesso das suas mais variadas formas de organização não carece, hoje, de grandes demonstrações. Cada vez mais respeitam-se países que alicerçam suas estratégias de desenvolvimento sobre ciência, tecnologia e inovação, superando modelos econômicos baseados em mão de obra barata ou produção de matéria-prima. O caminho que lhes é necessário percorrer para fugir à "armadilha da renda baixa" em ambiente de competição internacional globalizada é dificultado pela desigualdade de condições e de meios perante outros econômica, social e culturalmente mais desenvolvidos e, portanto, à partida, mais preparados para vencer. No entanto, uma forte e duradoura vontade política nacional, sustentada por uma consciência coletiva da importância da educação e do conhecimento, pode ser suficiente para alterar significativamente situações de desvantagem, mesmo em termos comparativos, durante o intervalo de tempo, relativamente curto, de uma geração (SANTOS; ALMEIDA FILHO, 2012).

Enunciar o objetivo de construir uma sociedade baseada no conhecimento, mesmo quando feito de uma forma determinada e convicta, o que nem sempre acontece, é apenas o primeiro passo, necessário e importante mas não suficiente, para a sua realização. Suposto dado este passo, a conceptualização do processo requer a prévia interpretação das especificidades e dos condicionalismos próprios de cada sociedade, já que a importação de modelos que se mostraram eficientes num outro contexto e a sua adaptação mecânica a uma nova realidade quase nunca é satisfatória. Depois, o maior ou menor sucesso da concretização, do desenvolvimento e da sustentabilidade de uma sociedade do conhecimento dependerão da forma como ele, conhecimento, se encontra mais ou menos disseminado, ou seja, das taxas de acesso à educação e à cultura nos mais variados níveis. Poder-se-á dizer, nesse contexto, que embora a atribuição de um Prêmio Nobel seja importante, como exemplo e catalisador do devir coletivo, pelo menos tão importante como ele é uma elevada taxa global de escolaridade, de graduação e de doutorado, sem descurar as áreas mais sensíveis de ciência e tecnologia. Como tal, uma política de desenvolvimento econômico implica hoje, obrigatoriamente, estratégias de inclusão escolar, na medida em que nenhuma sociedade pode desperdiçar suas inteligências, devendo proporcionar 
a todo cidadão acesso aos níveis de ensino e formação compatíveis com o desabrochar completo de suas potencialidades pessoais, independentemente dos recursos econômicos de que ele disponha.

Necessariamente diferentes, portanto, na forma e nos detalhes da sua adaptação a cada realidade, os novos modelos de desenvolvimento trazem igualmente vários traços de família: entre eles, a mobilização obrigatória dos sistemas científico e universitário, desejavelmente fortalecidos, e a aproximação entre os dois. Embora por vezes relegada a um lugar secundário de mera fornecedora de serviços a que a massificação do ensino superior, por um lado, e a supervalorização da cultura de massas, por outro, de certa forma a remeteram, a universidade não pode deixar de se assumir como sede de reflexão e de síntese criativa entre formação, pesquisa e inovação, para reforçar a sua posição de liderança intelectual da sociedade e reclamar a sua centralidade em todo o processo de desenvolvimento. Os países que mais se destacaram, ao longo do século XX, no plano da criação de riqueza e garantia de bem-estar dos cidadãos foram aqueles que souberam sabiamente conciliar a qualidade de uma formação superior massificada com as exigências específicas de uma formação especializada em ambiente de investigação científica de ponta, normalmente realizada em universidades.

Indo mais além nesse complexo processo de criação de riqueza no qual ocupa um lugar central, o papel e a importância da universidade saíram reforçados sempre que foi possível equilibrar judiciosamente à sua volta os ingredientes certos de juventude, criatividade, experiência e conhecimento, naquilo que agora se designa por Ecossistema de inovação, a base da Sociedade do conhecimento (BARON; SHANE; REUBER, 2008).

No contexto do esforço de reconstrução do pós-guerra, compreendendo que as limitações impostas pela fragmentação das fronteiras nacionais não os beneficiavam em termos da competição econômica global, os países europeus empreenderam um percurso notável de integração econômica e política, que evoluiu com naturalidade, com os avanços e recuos conhecidos, para uma interpretação supranacional do conceito de Sociedade do conhecimento. Foi nesse percurso, entretanto, seguido em outras latitudes também nas suas hesitações e nas suas dúvidas, e obviamente facilitado pelo extraordinário desenvolvimento e quase universal generalização das novas tecnologias, que as universidades de todo o mundo vieram encontrar um novo impulso para suas iniciativas de internacionalização. Hoje assistimos, 
em paralelo, ao lançamento pelas grandes universidades de programas internacionais de ensino a distância e ao crescimento sustentado dos índices de mobilidade acadêmica, em todos os níveis de formação e em todas as modalidades conhecidas, culminando com a criação de diplomas internacionais conjuntos, a constituição de equipes internacionais de pesquisa e o progressivo alargamento das experiências internacionais em todas as áreas de intervenção, clássicas ou contemporâneas, de uma universidade (ver, por exemplo, WARD, 2008).

Constituindo uma vasta rede de mais de 17 mil nós, vinculadas na sua diversidade aos mesmos princípios invariantes e universais que há séculos lhes conferem uma assinalável estabilidade, falando uma mesma linguagem de racionalidade e de diálogo, as universidades poderão igualmente tirar partido dessas suas características e potencialidades e utilizá-las ativamente como instrumento para a constituição de espaços supranacionais integrados do conhecimento, no plano do que poderá ser uma nova e nobre missão: a diplomacia cultural universitária. De certa forma, o rejuvenescimento institucional associado à emergência desta missão está para a crise da "universidade pós-moderna" como a terceira missão esteve para a crise da "universidade torre de marfim", ou como a segunda missão, para a crise da "universidade escolástica".

Um elevado número de autores, também no Brasil, tem se debruçado sobre a problemática da reforma universitária. Em Buarque (1993), por exemplo, encontra-se um veemente apelo à reforma, uma crítica intencional e certeira à universidade partindo das circunstâncias brasileiras que caracterizaram o último quartel do século passado, mas tantas vezes aplicável, com propriedade e justiça, a muitas outras latitudes. O objetivo deste estudo, que pretende inserir-se na mesma corrente reformadora, é contextualizar o papel da universidade na sociedade do conhecimento, com vistas a apresentar sugestões que contribuam para a sustentabilidade das instituições de educação superior do Brasil. Não porque elas sejam uma espécie ameaçada ou em vias de extinção - pelo contrário todos os indicadores convergem para uma garantida longevidade - mas porque pela mão dos que não querem reformas, ou dos que as esgotam na resolução dos seus próprios problemas, se vão criando condições para a progressiva redução da sua relevância social. Após um breve percurso pelas mais influentes reformas universitárias do último século, aspectos como a abrangência, 
a qualidade, a inovação e a internacionalização são relacionados entre si e apresentados como questões-chave, motivo obrigatório de reflexão e objeto de reforma que igualmente devem contemplar o alargamento da autonomia administrativa e financeira e a adoção de formas de governo mais responsabilizantes.

\section{A REFORMA DE GILMAN-FLEXNER E 0 ESPAC̣O EUROPEU DE EDUCAÇ̃̃O SUPERIOR}

As raízes da estruturação do sistema de educação superior que hoje prevalece em praticamente todo o mundo deve ser procurada na reforma levada a cabo em 1860 nos Estados Unidos, que o organizou em dois subsistemas: o primeiro, representado pela Universidade de Harvard e pela Universidade John Hopkins, então recém-criada por Daniel Coit-Gilman, dava prioridade à investigação científica e à formação humanística de alto nível, confirmadas através da outorga de títulos doutorais; o segundo, baseado na formação de quatro anos proporcionada pelos colleges, em cursos voltados para a cultura, a ciência e a arte, numa perspectiva mais pragmática ligada ao mercado do trabalho. Mais tarde, uma comissão constituída para avaliar o estado do ensino superior norte-americano na área da saúde, presidida por Abraham Flexner, preconizava que tais cursos constituíssem um pré-requisito para a entrada na universidade e embora inicialmente pensado apenas para a área da saúde, logo esse regime de ciclos era adotado em praticamente todas as instituições americanas de ensino superior. A influência do Relatório Flexner, publicado em 1910, pode ser atribuída ao seu certeiro diagnóstico da situação, baseado na visita que efetuou à totalidade das escolas médicas então existentes nos Estados Unidos e no Canadá, enfatizando a importância das bases científicas na prática médica e criticando a qualidade medíocre e os fins lucrativos de instituições e de professores (COOKE et al., 2006).

Mais recentemente, destaca-se com idêntica importância e influência a criação do chamado Espaço Europeu de Ensino Superior através de um movimento conhecido como Processo de Bolonha. Duramente criticado por uns, que nele viram a criação de mecanismos propiciadores da mercantilização do ensino superior, e idolatrado por outros, que nele projetaram, exageradamente, todas as suas expectativas de mudança, esse processo deu aos universitários europeus uma oportunidade de se sentirem 
ativos e participantes na construção da casa europeia e rapidamente se transformou numa extraordinária experiência viva de política internacional. Apesar de não ter sido iniciado nem conduzido diretamente sob os auspícios da União Europeia e de transcender em muito os seus limites geográficos, subscrito que está por 47 países, nem todos europeus, ele é um dos mais notáveis sucessos políticos da União, constituindo uma referência relativamente à qual os sistemas universitários das grandes economias do mundo se sentem obrigados a posicionarem-se. Esse êxito não deve ser desvalorizado.

O movimento, formalmente lançado em 1999, de cima para baixo, por ministros de 29 países que só tardiamente o abriram à corresponsabilização dos universitários, visava, inicialmente, concretizar os seguintes objetivos (EUROSTAT, 2009):

- A adoção de um quadro comum de qualificações baseada num regime de ciclos de estudo (dois, posteriormente alargado para três, com a inclusão do doutorado), facilmente legível e comparável;

- A remoção dos obstáculos à mobilidade através da Europa e a promoção da dimensão europeia na educação superior, quer em termos de conteúdos curriculares quer em termos de cooperação interinstitucional; e

- A criação de um sistema de créditos, ECTS - European Credit Transfer System, como meio de promover a mobilidade de estudantes e de facilitar a consideração de conhecimentos prévios obtidos fora da Europa.

Posteriormente, outros objetivos foram acrescentados ao processo, tais como:

- A promoção da aprendizagem ao longo da vida;

- O desenvolvimento de uma política de garantia da qualidade;

- O estabelecimento de ligações mais fortes entre o Espaço Europeu de Ensino Superior (EEES) e o Espaço Europeu de Investigação (EEI); e

- O reforço da dimensão social do EEES, traduzida pela noção de equidade a três níveis: equidade de acesso, equidade de tratamento e equidade de resultados (outcomes).

É difícil não ver nesses objetivos uma genuína preocupação em criar condições de contexto para que os vários sistemas nacionais de educação superior europeus, em toda a sua enorme diversidade, pudessem encontrar pontos de contato e referências comuns, permitindo uma articulação minimamente eficaz entre todos eles. Mais ainda do que as reformas de organização pedagógica que constituem as preocupações centrais do Processo de Bolonha, importa chamar a atenção para uma evolução das universidades europeias menos conhecida e que muitas vezes é confundida 
com ele. Em resposta a uma aspiração universitária que, em nossa opinião, antecedeu e precipitou a própria iniciativa dos ministros, as universidades europeias foram dotadas de estruturas de governo que lhes proporcionam a capacidade de se equacionarem já não como corporação de professores, de alunos ou de funcionários, ou de uma complexa mistura de interesses e de compromissos entre os três corpos, mas como entidades com unidade, missão, estratégia e objetivos próprios a prosseguir, aos quais se devem submeter, no quadro de uma autonomia responsável e, naturalmente, no cumprimento da lei, os interesses individuais, de corpo ou de grupo de todos os que a integram.

No contexto dessa pequena revolução e da profunda reflexão que a antecedeu e a acompanhou, bem sistematizada na série de oito Glion Colloquium até hoje realizados e respectivas publicações (WEBER; HIRSCH, 1999, 2001, 2202; WEBER; DUDERSTADT, 2004, 2006, 2008, 2010, 2012), compreende-se que o conceito de autonomia tem tanto de essencial para uma universidade como de potencialmente perverso, se for mal interpretado. Segundo Raposo (2005), “[...] a autonomia universitária é instrumento a serviço do bom desempenho da atividade educacional [...]", formulação que aqui abrange, naturalmente, toda a atividade universitária. A autonomia é atribuída pela sociedade à universidade na medida em que, e só na medida em que, isso facilite o funcionamento da segunda na concretização dos interesses da primeira. A regra da melhor realização do interesse público está, portanto, no cerne da justificação do conceito, como deve estar no cerne da decisão sobre o seu grau de distribuição em cascata pelos níveis inferiores de organização: faculdades, departamentos, grupos e professores. É necessário saber aproveitar os benefícios de uma correta e equilibrada distribuição dos diferentes tipos de autonomia (pedagógica, científica, administrativa, financeira, disciplinar, estatutária) pelos diferentes níveis da organização, sem que isso leve à desarticulação ou à descoordenação da estrutura universitária.

\section{A REFORMA NECESSÁRIA DA UNIVERSIDADE BRASILEIRA}

A análise comparativa das experiências norte-americana e europeia em matéria de educação superior, bem como a identificação dos principais desafios que ambas enfrentam nesse momento e a influência que em 
conjunto acabam por ter em quase todo o mundo constituem um bom pretexto e ponto de partida para um exercício de reflexão sobre o sistema de educação superior brasileiro. Nessa linha, faz sentido chamar a atenção para a urgência de uma reforma profunda dos sistemas de educação superior da América Latina e do Brasil em particular, apanhados na contramão da História (da qual a Europa do Sul fugiu, aliás, só recentemente), como os últimos bastiões do esquema de organização pedagógica de Napoleão (aliás, de Condorcet-Cabanis), baseado em percursos rígidos de formação universitária monolítica, conducentes à profissionalização. E embora seja legítimo e sempre útil refletir sobre as vantagens relativas de um e de outro sistema, a motivação para essa discussão está definitivamente reduzida a uma perspectiva meramente acadêmica já que, no plano do pragmatismo da organização dos sistemas nacionais de ensino, a posição de "orgulhosamente só" no mundo global em que a internacionalização universitária desempenha um papel cada vez mais importante é insustentável.

\section{Políticas para a inclusão}

Um dos aspetos que mais chama a atenção quando analisamos o sistema universitário brasileiro e o comparamos com o de outros países, tendo em consideração os respetivos níveis de rendimento individual médio, é a excessiva percentagem de estudantes matriculados em instituições privadas $\left(73,9 \%\right.$ em 2009) ${ }^{1}$. Dos países que alimentam as bases de dados internacionais sobre educação, por exemplo UNESCO, 2011, apenas a Coreia do Sul e o Japão têm percentuais superiores de matrícula em instituições privadas, mas esses dois países têm rendimento per capita três vezes superiores ao do Brasil (3,09 vezes, no caso do Japão, e 2,63 vezes, no caso da Coreia, dados de 2011). Os Estados Unidos, com 26,9\% de estudantes do ensino superior em instituições privadas têm um percentual três vezes menor que o Brasil, a Rússia (14,2\%), cinco vezes menor. Dentro da América Latina, a Argentina $(21,5 \%)$ apresenta um valor 3,4 vezes menor que o brasileiro, o México (33,1\%), 2,2 vezes menor e até o Chile $(65,4 \%)$, apesar de um percurso político muito influenciado por políticas neoliberais e um rendimento per capita 33\% superior ao brasileiro, tem percentualmente menos estudantes universitários em instituições privadas. Esse fato, associado ao elevado percentual de população brasileira em idade educacional (segundo AMARAL, $2011,45 \%$ da população tinha menos de 24 anos e 12\% tinha entre 18 e 
24 anos), tem como consequência inevitável baixos níveis de escolarização, quer medidos através da taxa líquida de escolaridade, de 14,6\% (AMARAL; CHAVES, 2011), quer através da taxa bruta de escolaridade, de 25,6\%, consubstanciando um ensino que tem que ser tecnicamente considerado elitista. O principal elevador social não está funcionando. O Brasil não está ainda a pagar o pesado tributo que tem para com os indígenas, os negros e, genericamente, os pobres. Não está, também, senão marginalmente, a aproveitar as potencialidades intelectuais de uma boa parte da sua população como fator de desenvolvimento.

Agravando este quadro de desigualdades deve acrescentar-se que, dos poucos jovens brasileiros que têm o privilégio de poder beneficiar-se de educação superior ( 1 em cada 7 jovens dos 18 aos 24 anos), apenas $24 \%$ deles (1 em cada 29), majoritariamente provenientes de estabelecimentos privados de educação média, fazem-no numa instituição pública de qualidade (federal ou estadual) e pagam $0,74 \%$ do custo total da educação que recebem, ou seja, $\mathrm{R} \$ 89$ por ano; enquanto isso, os restantes $76 \%$, normalmente provenientes de escola pública, frequentam uma instituição de menor qualidade, em muitos casos de qualidade muito duvidosa, e pagam $88,2 \%$ do seu custo, ou seja, R $\$ 7.719$ por $a n o^{2}$. Como esses números tornam evidente, a garantia constitucional de ensino universal e gratuito é apenas um conforto político que não desonera as famílias de uma pesada contribuição para a formação superior dos seus membros jovens, o que está a determinar um afastamento precoce do processo de formação.

Ora, o objetivo da universalização da educação superior, que tecnicamente está associado a uma taxa líquida de escolaridade de, pelo menos, $50 \%$, é o único compatível com os preceitos constitucionais brasileiros e com as exigências de uma economia baseada no conhecimento. Isso obriga a uma séria conscientização dessas dificuldades e a uma tomada de atitudes decididas para as ultrapassar. De entre elas, podemos referir:

- O aumento do número de instituições públicas de educação superior;

- O aumento do número de vagas das instituições públicas existentes;

- O aumento do universo de recrutamento, por melhoria da qualidade e da eficiência dos sistemas de educação básica (fundamental e média), sobretudo na rede pública;

- O aumento do universo de recrutamento, através da instalação de um sistema de creditação de conhecimentos informais obtidos em regime de autodidatismo, de prática profissional ou de experiência de vida; e 
- A generalização da política de bolsas para frequência de instituições privadas de educação superior.

\section{Políticas para a qualidade}

A abrangência dos sistemas educacionais não pode estar desacoplada da qualidade da educação que proporcionam. No ensino básico, o índice brasileiro Ideb - Índice de Desenvolvimento do Ensino Básico resolve bem essa questão ao associar um indicador qualitativo (informações de desempenho escolar em exames padronizados) com um indicador quantitativo (informações sobre rendimento escolar, ou seja, aprovações), sendo, nesse nível de ensino, os dois aspetos essenciais para proporcionar às universidades uma base de recrutamento suficientemente abrangente.

A questão coloca-se de maneira análoga na educação superior. Com efeito, não interessa ao país manter as atuais taxas de repetência ou de abandono, excessivamente elevadas, mesmo que isso signifique uma boa preparação daqueles que concluem a sua graduação, bem como não interessa aumentar as taxas de aprovação à custa da diminuição do grau de exigência. Aumentar a quantidade sem diminuir a qualidade é uma equação que parece de difícil solução. No entanto, a comparação entre os diversos sistemas nacionais mostra que os países com taxas de escolaridade mais elevadas são também aqueles em que as taxas de graduação são mais altas (SANTOS; ALMEIDA FILHO, 2012). Sobre a diminuição de qualidade provocada pela massificação do ensino parece, pois, prevalecer o efeito de maturidade do sistema que induz uma correlação positiva entre quantidade de estudantes e sucesso escolar. Ou seja, os resultados apresentados parecem indicar que um sistema mais abrangente é igualmente mais eficiente em percentagem de graduações e que esse efeito prevalece sobre o de uma eventual degradação da qualidade.

É, portanto, de um novo paradigma de organização para a qualidade que precisamos, apoiado em duas abordagens distintas e complementares: i) a intervenção a montante do sistema, proporcionando uma base regulamentar suficientemente detalhada para evitar desvios comprometedores da qualidade; e ii) o funcionamento de sistemas adequados de gestão da qualidade ou de avaliação de desempenho que permitam aferir o funcionamento dos cursos e, no caso vertente, os conhecimentos e as capacidades adquiridos pelos estudantes. 
Essa atitude não releva de considerações de natureza ideológica. Em todo o mundo, os países de tendência liberal, à partida mais disponíveis para desregulamentar, são os que levam mais a sério o controle de qualidade da educação superior, quer através de regulamentação do sistema quer através de práticas formais de avaliação. No caso europeu recente, foi a partir deles que essas práticas se generalizaram em todo o continente. Curiosamente, as maiores preocupações de natureza social são frequentemente acompanhadas pela tendência para abrandar o grau de exigência, aproveitando abusivamente o conceito de autonomia para deixar essas questões ao livre arbítrio das instituições, dentro das quais elas acabam por ser desconsideradas, por influência perversa de interesses corporativos ou de grupo. Ora, não é difícil compreender que, no quadro de uma autonomia responsável a serviço dos interesses da sociedade, quanto mais generosa for a interpretação do conceito, mais cuidadoso deverá ser o seu quadro regulamentar e mais rigoroso o sistema de avaliação ao qual deve responder. Isso acontece mesmo nos países mais desenvolvidos, sejam eles liberais ou não.

É igualmente importante referir que a qualidade universitária não tem que estar reservada às instituições públicas como, com raras exceções, acontece atualmente no Brasil. Provam-no o fato de as melhores universidades do mundo serem de natureza privada, embora muitas delas subsidiadas pelo Estado e quase todas sem fins lucrativos. Mas ela está, seguramente, reservada aos países que levam a sério a educação, que equacionam os sistemas universitários de uma forma objetiva e coerente e que têm a coragem de fazer as reformas necessárias, mesmo quando isso implica contrariar interesses instalados. E fazem-no tanto em nível regulamentar, ab anteriori, como em nível de avaliação, a posteriori, dos cursos, dos grupos de pesquisa e das instituições (públicas ou privadas).

Instituições públicas e privadas podem coexistir e ambas podem participar no esforço coletivo nacional, em concretização do interesse público, para elevar drasticamente as qualificações médias dos cidadãos. Dificilmente o país o poderá fazer, aliás, se tiver como única via a escola pública. Mas a qualidade da educação proporcionada terá de ser um aspecto determinante na definição das políticas públicas de autorização de funcionamento das instituições (públicas e privadas) e de atribuição de bolsas de estudo aos seus alunos.

Algumas medidas devem ser tomadas:

- A progressiva generalização a todo o sistema (instituições públicas e privadas, confessionais e comunitárias) e a todas as atividades universitárias 
(graduação, pós-graduação e pesquisa) das melhores metodologias e práticas de avaliação já existentes, tornando-as sempre, o que agora não acontece, efetivas e fiáveis;

- A valorização, no contexto da avaliação dos cursos, tanto das taxas de aprovação como do grau de conhecimentos adquiridos pelos estudantes, aferido em termos nacionais, por exemplo, através do Enade e das classificações nos exames nacionais de acesso às associações profissionais; e

- A utilização dos resultados gradativos das avaliações, como critérios para autorização do funcionamento dos estabelecimentos e para atribuição de bolsas de estudos aos seus alunos.

\section{Políticas para a inovação}

Durante a Segunda Guerra Mundial, com a incorporação tecnológica no esforço de guerra, a investigação científica impôs-se decididamente como "assunto de Estado" sendo os norte-americanos pioneiros na compreensão da importância da Ciência e da Tecnologia para o desenvolvimento econômico e social. Desse fato, aproveitado no âmbito de uma grande reforma universitária empreendida, como vimos, desde o início do século $\mathrm{XX}$, resultaram simultaneamente o reforço da componente da investigação científica na universidade e a emergência na instituição de um novo conjunto de preocupações que, progressivamente, foram se consolidando sob a designação de atividades de prestação de serviços, de extensão, de transferência e de inovação. Dele decorreu igualmente, também nos Estados Unidos, o desenvolvimento de um novo paradigma de financiamento das universidades, tornado cada vez mais dependente de agências de financiamento da investigação científica e referenciado pelo mercado do trabalho e pela prestação de serviços especializados e, em consequência, pelo progressivo aumento do peso relativo do investimento contratualizado relativamente ao investimento fechado, e do privado relativamente ao público.

A universidade chamava a si uma nova responsabilidade, que hoje se aceita constituir a sua terceira missão ${ }^{3}$, vinculada a uma tomada de consciência do seu papel de instituição indutora do desenvolvimento econômico e social, através da inovação tecnológica, e também promotora de mudança social e cultural. Nessa perspectiva ampla, que se poderia genericamente designar por compromisso social da universidade, faz sentido incorporar os pontos 
da agenda universitária que têm a ver, por exemplo, com a inclusão social, com a sustentabilidade, com o ambiente e com a cultura.

Todos os universitários conhecem bem essa história mas alguns, agarrados ao conceito de universidade que ela, justamente, ultrapassou, não estão ainda disponíveis para a compreender até as últimas consequências. Abandonar a "universidade torre de marfim" significa desfazer as barreiras que durante 200 anos a mantiveram resguardada, à margem da sociedade. Significa disponibilidade e desejo de ir a jogo, de participar nos desafios para os quais a sociedade a interpela, de não ter receio de se expor ao mundo, com todas as suas virtudes e todas as suas limitações, de deixar cair a proteção de quem fala de cátedra, de usar apenas o peso da argumentação que o nosso conhecimento puder proporcionar e de aceitar, sempre, a réplica de outros.

Significa ser instrumento de valorização cultural das comunidades, de apoio técnico e científico em projetos por elas promovidos, vetor de modernização das organizações, mas significa também preparar os jovens para o mundo das empresas, da transferência e da inovação, através de programas de formação em empreendedorismo, da definição de uma política de defesa da propriedade intelectual, do apoio às atividades das empresas júnior, da criação de empresas start-up e spin-off.

Significa não ter uma relação difícil com o dinheiro, não ver com maus olhos a contratualização de atividades de investigação pura ou aplicada, ou a prestação de serviços especializados, não repudiar a angariação de receitas próprias nem criticar, antes promover, o aumento de receita universitária através da componente contratualizada no seu orçamento e a valorização relativa dos professores que diretamente contribuem para isso.

Sintetizando, a evolução da universidade brasileira no campo das atividade de inovação requer atenção para os seguintes pontos:

- O alargamento do conceito de extensão universitária às práticas de empreendedorismo e inovação;

- A valorização das atividades de extensão na grade de avaliação dos professores, em nível semelhante às de docência e de pesquisa, e a creditação dessas atividades aos estudantes que as desenvolvam;

- $\mathrm{O}$ incentivo às atividades das empresas júniores;

- A criação de incubadoras de empresas e o incentivo à criação de empresas envolvendo professores e estudantes, com base em ideias de negócio surgidas no âmbito das atividades de docência e de pesquisa; 
- A definição de políticas institucionais de valorização da propriedade intelectual, incluindo incentivos individuais à defesa de patentes numa base institucional;

- A valorização da criação de sinergias com a indústria, passando pela criação de laboratórios de interface e de programas de formação específicos em áreas de ponta; e

- A realização de licenças sabáticas em contexto empresarial.

\section{Políticas para a internacionalização}

A concepção inovadora do sistema científico e universitário, capaz de colocar o saber a serviço da produção de riqueza, contribuiu decisivamente para conferir aos Estados Unidos uma capacidade econômica sem precedentes, que lhe proporcionou condições de bem-estar individual e coletivo e a capacidade de se tornar a primeira potência mundial.

Fora da órbita direta americana, o mundo demorou 50 anos para reagir. Na Europa, embora algumas universidades tivessem incorporado rapidamente o conceito subjacente à terceira missão, só muito tardiamente se compreendeu não ser possível resistir ao domínio avassalador dos Estados Unidos a não ser criando propósito, dimensão e ambição no seu sistema científico e universitário. Após várias iniciativas de âmbito mais restrito, em 1999 a Europa decidiu avançar para a constituição do Espaço Europeu de Ensino Superior, conceito que um ano mais tarde alargou para o de Espaço Europeu do Conhecimento e da Inovação, com a integração de políticas comuns de ciência e de tecnologia. A contribuição da Europa nessa matéria foi, portanto, a de ter evidenciado que a construção de uma economia moderna competitiva requeria um ganho de dimensão em todo o edifício do conhecimento, objetivo que, num espaço politicamente fragmentado como o europeu, só poderia ser atingido internacionalizando o sistema científico e o sistema universitário tanto quanto se tinha já internacionalizado o sistema econômico e o sistema financeiro.

É interessante verificar como se situa o resto mundo perante esses dois modelos. Os países que, pela sua dimensão, constituem autonomamente espaços econômicos viáveis, ou ainda os que não sabem ou não podem associar-se com outros, parecem privilegiar uma via autônoma ou autocentrada de desenvolvimento semelhante à dos Estados Unidos. Estão nesse caso a China, a Índia e a Rússia ${ }^{4}$. Para esses países, a internacionalização de seus 
sistemas científico e universitário significa, sobretudo, uma competição muito dura e nem sempre cordial para captar cérebros ou ideias.

No Sudeste Asiático, através da Asean (Association of Southeast Asian Nations) e, sobretudo, na América Latina, através do Mercosul (Mercado Comum do Sul), a estratégia parece ser mais próxima da europeia. Porque não existe (ou enquanto não existe?) em nenhum desses três espaços uma economia esmagadoramente dominante ou com suficiente dimensão de mercado para poder competir isoladamente em termos globais, as decisões poderão passar pelo favorecimento da aproximação das economias e pela criação, numa base regional, de um espaço integrado do conhecimento. Por isso, as experiências de internacionalização universitária mais evoluídas e politicamente mais significativas e ambiciosas, embora em estádios de desenvolvimento muito diferentes, podem hoje ser encontradas na Europa e na América Latina, que parecem ser as regiões do mundo que melhor compreendem e interpretam de forma mais abrangente a internacionalização universitária, talvez porque sejam as que mais têm a se beneficiar com ela em relação ao seu desenvolvimento de médio e de longo prazo.

Mas os dados estão longe de estar lançados. Por um lado, porque a criação de espaços econômicos fortes na América Latina e no Pacífico que excluam os Estados Unidos não se fará sem dificuldades. Provam-no a criação da Alca (Área de Livre Comércio das Américas) e a refundação da Apec (Asia-Pacific Economic Cooperation), ambas por iniciativa dos Estados Unidos, em 1994, que têm sido interpretadas como tentativas de abrandar a atividade e diminuir a importância do Mercosul e da Asean e de reforçar a posição dos Estados Unidos numa e noutra região. Por outro lado, porque a inexistência, na América Latina, como acima se diz, de uma economia esmagadoramente dominante - fato propiciador ao desenvolvimento de uma estratégia de integração - é uma verdade, porém com tendência para deixar de o ser.

Como resultado, a opção do Brasil nessa matéria parece ter-se modificado, nos últimos anos, entre a adoção de uma estratégia de equipe, favorecendo a criação de espaços integrados de conhecimento mais alargados, optando por ser na América Latina o que a Alemanha é (ou deveria ser) na Europa, e a assunção da sua posição internacional individual de potência emergente, privilegiando um modelo de internacionalização semelhante ao dos Estados Unidos, da China, do Japão ou da Índia. No que diz respeito 
à política universitária, essa indecisão entre duas vias de desenvolvimento manifesta-se, por exemplo, por um lado, com a criação da Unila (Universidade Federal da Integração Latino-Americana, em Foz do Iguaçu, Paraná) e da Unilab (Universidade Federal da Integração Internacional da Lusofonia AfroBrasileira, em Redenção, Ceará), consideradas como verdadeiras universidades do Mercosul e da Comunidade dos Países de Língua Portuguesa - CPLP, respectivamente, e, por outro, com as opções tomadas pelo Programa Ciência sem Fronteiras, oportunidade única e irrepetível para cimentar Espaços Integrados do Conhecimento em que virtualmente nenhuma universidade da América Latina ou da África é considerada parceira e a existência do Mercosul e da CPLP é, simplesmente, ignorada.

Da resolução dessa alternativa entre julgar-se com dimensão e momento para tentar a fuga sozinho ou procurar apoio em outros parceiros para descolar do pelotão em grupo dependerá, em larga medida, o futuro de estruturas integradoras com o Mercosul ou a CPLP. Mas a disjunção não tem que ser exclusiva. Quaisquer que sejam, no futuro, a forma e a composição das várias regiões econômicas, a importância e a valorização de cada país dentro da região a que pertence dependerá, também, da influência que consiga ter fora dela ou, dito de outra forma, dos laços que, por seu intermédio, seja possível estabelecer entre as várias regiões. O oposto é igualmente verdadeiro. A credibilidade internacional de uma grande potência e, com mais razão, de uma potência emergente como o Brasil dependerá, no tabuleiro em que só jogam os grandes, da capacidade que tiver para estabelecer pontes com os seus vizinhos diretos (geográficos, históricos, linguísticos ou outros) e para patrocinar consensos entre eles, ou seja, na terminologia crua dos camarins da diplomacia, da capacidade de manter arrumado o seu quintal, mesmo que a cerca não esteja muito bem definida, mesmo que alguns, estando já dentro, ainda pensem que estão fora.

Deste complexo e imprevisível jogo de xadrez internacional surge um campo de oportunidades praticamente inesgotável para as universidades que souberem tirar partido das suas características próprias e de grupo. Notadamente, para as mais capazes de adicionar a suas lógicas nacionais, sem sobrepo-las, as que decorrem de um outro tipo de competências relacionais de caráter internacional que, no caso das universidades, são geneticamente fundadas numa mesma linhagem histórica e culturalmente alimentadas por uma mesma linguagem, que é a linguagem da racionalidade e da ciência. 
Seja qual for o caminho que escolham ou os estímulos a que respondam, ou qualquer outra possível consideração de natureza política ou ideológica, de origem ou de antiguidade, de localização geográfica ou de opção estratégica, as universidades estão hoje confrontadas com uma inevitabilidade histórica. Nem todas no mesmo momento, nem todas ao mesmo nível ou com a mesma intensidade mas, se quiserem ocupar no século XXI o lugar central que para elas reserva a comunidade em que se inserem, no contexto da criação de uma sociedade do conhecimento, as universidades não poderão deixar de se abrir à cooperação e colaboração internacionais para as quais, aliás, vêm sendo preparadas ao longo dos séculos.

De fato, todas as atividades de uma universidade podem ser valorizadas por recurso à colaboração universitária internacional (ver, por exemplo, MOROSINI, 2011). Para além de nos tornar menos provincianos e menos autocentrados, menos deslumbrados pelo brilho do nosso sucesso local e mais atentos ao que se passa à nossa volta, essa prática que nos desumbiga - a colaboração universitária internacional - fornece ainda os meios para um novo, riquíssimo e praticamente inesgotável campo de oportunidades:

- Como complemento educacional para os estudantes, em todos os níveis de formação, quer no plano da preparação técnica das matérias dos respectivos cursos, quer no plano da formação linguística, cultural, cívica e civilizacional que pode constituir uma experiência de vida num país diferente, particularmente marcante quando se tem 20 anos;

- Como complemento às competências individuais ou de grupo, em busca de fertilizações cruzadas na composição de equipes de pesquisa mais alargadas; e

- Como manancial para troca de experiências, para aferição de instrumentos e de métodos, para avaliação de resultados, em todos os campos da atividade universitária.

O momento em que a internacionalização universitária passa a constituir uma verdadeira alteração de paradigma consubstanciada na criação de um quadro de trabalho profundamente inovador e não apenas uma melhoria do que já existe é quando ela se torna o cimento agregador de todas as restantes atividades da universidade a serviço de uma estratégia própria que tire partido das suas especificidades, definindo e concretizando uma agenda autônoma de diplomacia cultural universitária, no quadro da criação de um espaço alargado, transnacional, de conhecimento (ver SANTOS; ALMEIDA FILHO, 2012). Exercida nos moldes que cada universidade 
define, na prossecução de objetivos que só a ela compete estabelecer, a internacionalização será mais um fator a garantir a diversidade do sistema. Ela é, portanto, simultaneamente, uma manifestação e um vetor da autonomia já que, por um lado, não existiria sem autonomia e por outro, a reformula, a concretiza e a impõe.

As universidades brasileiras precisam estar preparadas para exercitar a internacionalização nessa perspectiva abrangente. Para isso, é necessário:

- A compreensão pelos seus dirigentes de que só essa visão ampla dos desafios internacionais a que a universidade tem de responder lhes permite situarem-se na primeira linha da universidade mundial;

- A nomeação de um Pró-Reitor, tal como acontece com a graduação, a pós-graduação e a pesquisa, com competências para conduzir as atividades de internacionalização;

- A eliminação de todas as barreiras artificiais internas à mobilidade, com a redefinição racional dos mecanismos que a promovem e o absoluto compromisso de creditar aos estudantes o conhecimento adquirido no exterior; $\mathrm{e}$

- A criação ou fortalecimento de um serviço administrativo específico para apoio às atividades de internacionalização.

\section{Políticas para um governo mais eficiente da universidade}

Embora as reformas universitárias, tais como as outras, não se copiem, também não se podem ignorar os significativos avanços que elas proporcionam aos que as empreendem em tempo. Fazê-lo significaria deixar acentuarem-se as diferenças entre os chamados custos de contexto dos diferentes países, cavando o fosso entre níveis de desenvolvimento, num processo de divergência econômica e social cujas primeiras causas se podem procurar no desempenho dos sistemas científico e universitário, como reflexo e pedra de toque de todo o sistema educacional, e as últimas consequências se encontram (ou não) na qualidade de vida dos cidadãos.

Não é coerente admirar a Universidade de Harvard, ou o MIT, ou Carneggie Mellon, ou Oxford, ou Cambridge, ou tantas outras que se encontram no grupo das melhores universidades do mundo e continuar, nas nossas, a defender formas arcaicas de gestão ou a torcer o nariz sempre que elas acedem, pelo trabalho dos seus dirigentes ou dos seus integrantes mais dinâmicos, a financiamentos abertos que são, precisamente, os que melhor demonstram a sua capacidade de se colocar a serviço da sociedade. 
A reflexão sobre a forma de governo da universidade não deve ser separada da compreensão da fonte de poder, ou de legitimidade, que o suporta, e essa questão está indissociavelmente ligada ao conceito de autonomia. A autonomia da universidade, que surge no início do século XIX associada à reforma de Humboldt, é reclamada no contexto de uma reflexão e sistematização teórica sobre a necessidade de remover os últimos resquícios do caráter sacro da universidade, bem como impedir a ingerência do Estado sobre o seu funcionamento (KANT, 1798). Nascida desse movimento, ela tem por vezes tendência para não respeitar as origens, assumindo ela própria, na reflexão de quem não a entende ou a desvirtua em benefício próprio, um certo caráter de sacralidade. Considerada desde então indispensável ao bom desempenho da universidade, a autonomia é apenas um instrumento que lhe é conferido para que ela possa (poder-se-ia igualmente dizer enquanto isso contribuir para que ela possa, ou ainda, na justa medida em que isso contribua para que ela possa) melhor desempenhar a sua missão. A autonomia não é um estatuto para sempre adquirido pelas universidades, antes deve ser permanentemente escrutinado pela comunidade, a cujas regras elas devem considerar-se vinculadas e a cujos desígnios devem, em última análise, responder.

Ora, a atividade das universidades não pode deixar de ser exercida num quadro legal bem definido, que trace objetivos e imponha regras, sendo que a eficiência global do sistema depende, em larga medida, da clarificação dessas regras e da adequada distribuição das responsabilidades entre os vários intervenientes. De fato, a ausência de regras sempre favorece a concorrência desqualificada, o que conduz ao nivelamento por baixo e portanto, à diminuição da qualidade. Por outro lado, não é razoável esperar-se que os problemas resolvam-se através de mecanismos de autorregulação, como a atual crise mundial do sistema financeiro, deixado demasiado tempo entregue a si mesmo e às chamadas regras de mercado, aí está para demonstrar.

Nesse contexto, a comunidade universitária, que interpreta e concretiza no dia a dia o conceito de autonomia, não pode se assumir como a fonte do poder universitário, na medida em que a universidade não existe para realizar os objetivos da sua comunidade restrita, mas sim os de toda a sociedade. A forma de governo universitário e de escolha dos seus dirigentes não pode deixar de refletir a origem da sua legitimidade democrática. 
Equacionada essa questão, retiramos das melhores universidades da atualidade a capacidade que têm demonstrado para:

- Selecionar objetivos, não muitos, o que significa obrigatoriamente deixar de fora ou secundarizar alguns deles;

- Definir metas que permitam avaliar o grau de execução dos objetivos traçados;

- Refletir sobre os estrangulamentos que afetam o nosso desenvolvimento;

- Confrontar e vencer interesses ilegítimos instalados;

- Libertar-se de preconceitos e abrir-se à mudança;

- Procurar soluções e ter coragem para as experimentar;

- Mostrar disponibilidade para correr riscos; e

- Assumir um comportamento despojado e humilde para admitir os erros e para corrigir as trajetórias.

Numa questão tão complexa como a do governo de uma universidade não se espera que fórmulas mágicas que permitam resolver, de uma vez, todos os problemas surjam. Cremos, no entanto, que a reforma do governo da universidade brasileira deverá fazer-se de acordo com as seguintes orientações:

- Encontrar a figura jurídica adequada que possa dar suporte ao conceito de autonomia universitária, convenientemente dimensionado e clarificado em todos os seus contornos (sendo os mais polêmicos os de natureza administrativa, financeira e patrimonial), num consenso social e político que se torna indispensável à concretização dos fins de uma universidade moderna;

- Trazer para dentro da universidade a representação dos interesses da sociedade sob a forma de um Conselho Superior de Autonomia, órgão de encontro e conciliação entre as posições da universidade e as da sociedade, que garanta à primeira maior liberdade de movimentos e a não intervenção externa sobre aspectos da sua vida corrente e, à segunda, a correta utilização dos recursos públicos; esse Conselho teria, exclusivamente, competências para intervir na eleição do Reitor e, em consequência, na definição das orientações estratégicas (por exemplo escolhendo-o de uma lista tríplice que lhe é apresentada pela universidade, com seus respectivos planos de atividades, contendo programas de gestão, objetivos, prioridades e metas) e poderes de supervisão dos órgãos dirigentes (aprovação de Planos de Atividades e de Relatórios de Contas);

- Reforçar a capacidade de liderança dos Reitores dando-lhes, em última análise, a capacidade de veto sobre decisões de órgãos colegiados, sempre que estas contrariem ou impeçam a concretização dos objetivos expressos nos Planos de Atividades aprovados pelo Conselho Superior de Autonomia; 
- Reforçar a componente plurianual do financiamento para possibilitar a realização de planos de ação de médio prazo e, notadamente, o lançamento de programas de investimento;

- Reforçar a componente aberta do financiamento, contratualizado com as instituições em função de objetivos a atingir (número de vagas, taxas de diplomação, classificações relativas nos exames de âmbito nacional ou internacional, número de artigos científicos publicados e respectivas citações, etc.);

- Responsabilizar os dirigentes pelo não cumprimento dos Planos de Atividades; e

- Criar sistemas de incentivo às boas práticas profissionais de professores, estudantes e funcionários e de oneração moral e disciplinar no não cumprimento e desleixo profissionais.

Triturada na lógica dicotômica, quase sempre influenciada por pressupostos de natureza ideológica que opõem o bem público (universal e gratuito) ao bem privado (com valor de mercado a que só acede quem pode), a universidade brasileira tem visto cavar-se o fosso que a separa do tempo em que vive e, embora com algumas exceções, perdeu 50 anos alinhada por um modelo que, já na altura, as maiores referências da educação brasileira teriam conseguido reformar (UNIVERSIDADE DE BRASÍLIA, 1962; RIBEIRO, 2012) não fosse a lamentável interrupção da experiência por conta da ditadura militar.

Algumas das medidas enunciadas podem parecer inatingíveis. Mas não fazer nada seria trair a memória dos pioneiros, que já há 50 anos foram capazes de recolher, com inteligência e critério, o que lhes pareceu adequado do modelo norte-americano e construir uma universidade sob a forma de uma fundação, com capital fundacional próprio que lhe teria proporcionado - era essa a intenção, infelizmente não concretizada - reforço da capacidade de liderança e verdadeira autonomia administrativa e financeira. O que se propõe não poderia, portanto, ser menos radical: recuar 50 anos, revisitar os textos legais que deram corpo à criação da UnB, refletir sobre a sua tremenda atualidade, mas necessária atualização, perceber que o caminho foi interrompido apenas para resolver problemas de conjuntura política e que está na hora de o retomar.

Esse caminho não pode, no entanto, ser trilhado por todas as universidades ao mesmo tempo. Nem todas as universidades brasileiras estariam, nesse momento, em condições de aceitar o desafio. Mas num programa faseado em, por exemplo, dez anos, não seria difícil fazer migrar para esse sistema organizacional um conjunto consistente de universidades particularmente bem posicionadas para liderarem o processo, constituindo uma espécie de locomotiva do sistema e de farol para todas as outras, no contexto de uma reforma universitária que se faz necessária. 


\section{REFERÊNCIAS}

AMARAL, N. O novo PNE e o financiamento da Educação no Brasil: os recursos como um percentual do PIB. In: SEMINÁRIO DE EDUCAÇÃO BRASILEIRA, 3., 2011, Campinas. Anais.... Campinas: Cedes, 2011. Disponível em: <http:/ /www.cedes.unicamp. br/seminario3/nelson_amaral.pdf $>$. Acesso em: jan. 2012.

AMARAL, N.; CHAVES, V. A educação superior no Brasil: os desafios da expansão e do financiamento. In: CONFERÊNCIA DO FORUM DA GESTÃO DO ENSINO SUPERIOR NOS PAÍSES E REGIÕES DE LÍNGUA PORTUGUESA, 1., 2011, Lisboa. Anais... Lisboa: Universidade de Lisboa, 2011. Disponível em <www.slidefinder.net/n/ nca_vjc/32707620>. Acesso em: abr. 2012.

BARON, R., SHANE, A.; REUBER, A. Entrepreneurship, A Process Perspective. 1st Canadian ed. Alexa Rank: Nelson Education Ltd., 2008.

BUARQUE, C. A Aventura da Universidade. São Paulo: Editora UNESP, 1993.

COOKE, M. et al. American Medical Education 100 Years after the Flexner Report. New England Journal of Medicine, Waltham, v. 355, n. 13, p. 1339-1344, 2006. Disponível em: <www.nejm.org>. Acesso em: abr. 2012. http://dx.doi.org/10.1056/NEJMra055445

EUROSTAT. The Bologna Process in Higher Education in Eutope. Key indicators on the social dimension and mobility. Eurostat \& Eurostudent, 2009.

MOROSINI, M. C. Internacionalização na produção de conhecimento em IES brasileiras: cooperação internacional tradicional e cooperação internacional horizontal. Educação em Revista, Belo Horizonte, v. 27, n. 1, p. 93-112, 2011. http://dx.doi.org/10.1590/ S0102-46982011000100005

KANT, I. O Conflito das Faculdades. Lisboa: LusoSofia Press, 1798. Covilhã. 2008. Disponível em: <http://www.lusosofia.net/textos/kant_immanuel_conflito_das_faculdades.pdf>. Acesso em: 09 maio 2012.

RAPOSO, G. R. A educação na Constituição Federal de 1988. Jus Navigandi, Teresina, ano 9, n. 641, 10 abr. 2005. Disponível em: <http://jus.com.br/ revista/texto/6574/aeducacao-na-constituicao-federal-de-1988>. Acesso em: 09 maio 2012.

SANTOS, F.; ALMEIDA FILHO, N. A Quarta Missão da Universidade. Brasília: Ed. UnB, 2012. RIBEIRO, D. (Org.). Universidade de Brasilia: projeto de organização, pronunciamento de educadores e cientistas e Lei no 3998 de 15 de Dezembro de 1961. 1. reimpr e ed. esp. Brasília: Editora UnB, 2011.

UNESCO. Global Education Digest. Paris: UNESCO, 2011. Disponível em: <www.uis.unesco. org/Education/Pages/ged-2011.aspx>. Acesso: abr. 2012.

UNIVERSIDADE DE BRASÍLIA - UnB. Plano Orientador da Universidade de Brasília. Editora UnB. Brasília. 1962.

WARD, D. Globalization, Public Policies and Higher Education. In: WEBER, L.; DUDERSTADT, J. (Orgs.). The Globalization of Higher Education. London: Economica, 2008. cap. 24. (Glion Colloquium VI).

WEBER, L.; HIRSCH, W. (Eds.). Challenges Facing Higher Education at the Millennium. London: Economica, 1999. (Glion Colloquium I).

WEBER, L.; HIRSCH, W. Governance in Higher Education. London: Economica, 2001. (Glion Colloquium II). 
WEBER, L.; HIRSCH, W. As the Walls of Academia are Trumbilg Down. London: Economica, 2002. (Glion Colloquium III).

WEBER, L.; DUDERSTADT, J. Reinventing the Research University. London: Economica, 2004. (Glion Colloquium IV).

WEBER, L.; DUDERSTADT, J. University and Business: Partnering for the Knowledge Society. London: Economica, 2006. (Glion Colloquium V).

WEBER, L.; DUDERSTADT, J. The Globalization of Higher Education. London: Economica, 2008. (Glion Colloquium VI).

WEBER, L.; DUDERSTADT, J. University Research for Innovation. London: Economica, 2010. (Glion Colloquium VII).

WEBER, L.; DUDERSTADT, J. Global Sustainability and the Responsibility of Universities. London: Economica, 2012. (Glion Colloquium VIII).

\section{NOTAS}

${ }^{1}$ Amaral e Chaves (2011) apresentam um número ligeiramente diferente (74,4\% em 2009). Optamos por utilizar aqui o valor constante das bases de dados internacionais por uma questão de maior robustez na comparação internacional. De qualquer forma, as diferenças são pequenas.

${ }^{2}$ Elaboração do autor com base em valores obtidos de Amaral e Chaves (2011).

${ }^{3} \mathrm{O}$ ensino constitui a primeira missão da universidade e a pesquisa a sua segunda missão.

${ }^{4}$ O Japão e Taiwan, diretamente dependentes dos Estados Unidos desde o final da Segunda Guerra Mundial, bem como Singapura, Coreia do Sul e Hong-Kong, igualmente muito influenciadas pelo "gigante americano", foram capazes de responder precocemente a esses desafios já que se alinharam desde muito cedo com o modelo de organização universitária americana. Esse fato, ao qual não podemos esquecer de acrescentar a adoção de medidas agressivas da "cartilha" liberal para atrair capital estrangeiro - inicialmente apoiadas na mão de obra barata e disciplinada, na isenção de impostos e nos baixos custos de instalação de empresas, terá contribuído para o sucesso econômico dos chamados "tigres asiáticos", particularmente visíveis a partir do início dos anos 80 do século XX.

Recebido: $24 / 10 / 2012$

Aprovado: 06/03/2013 